\title{
A FORMAÇÃO DO PROFESSOR UNIVERSITÁRIO DE HISTÓRIA
}

\author{
Luiz Fernando Silva Prado* \\ Ifsprado@yahoo.com.br
}

Resumo: o presente artigo pretende refletir, historicamente, a problemática da formação do professor universitário de História, no Brasil, centrada na bipolaridade ensino/pesquisa como "ethos acadêmico" que sustenta a idéia de Universidade.

Palavras-Chave: história, educação, formação de professor

A formação do professor do Ensino Superior deve ser pensada segundo suas especificidades e os contextos institucionais que a determinaram. Portanto, um estudo sobre este tema remete, necessariamente, à compreensão dos diversos modelos que deram origem à ideia de Universidade, bem como a de sua natureza e identidade no transcorrer de seu desenvolvimento histórico. Com isso, um estudo a este respeito necessita de um repertório mais contundente e, conseqüentemente, de um espaço considerável para as devidas reflexões, incabível neste artigo. No entanto, é reconhecido, ainda hoje, que o princípio básico que sustenta a própria razão da existência da Universidade encontra-se na articulação de suas funções primordiais: a pesquisa, o ensino e a extensão.

Essas pontuações preliminares são significativas quando se pretendente discutir a questão da formação do professor desse nível de ensino e os objetivos educacionais das instituições responsáveis pela formação da docência no nível superior.

No caso da universidade brasileira, o seu surgimento tardio conferiulhe características próprias e um status diferenciado de suas correlatas mundiais. Gerada no contexto do desenvolvimento do capitalismo na sua fase moderna (anos 1930), a Universidade brasileira enfrenta, além da ausência de uma tradição acadêmica, sinais de crise revelados pelas demais Universidades, entre eles: a demanda da expansão de ensino e a presença cada vez mais acentuada de instituições particulares voltadas, preponderantemente, para o mercado lucrativo, contribuindo, assim, para o processo de massificação do ensino superior.

${ }^{\star}$ Doutorando em História pela UFG. Professor de História da Universidade Estadual de Goiás. 
Diante dessa situação de crise geral e, em particular, daquela específica à realidade universitária brasileira, como pensar no "ethos acadêmico" que sustenta a idéia de Universidade, ou seja, seu direcionamento para o ensino e a pesquisa?

No Brasil, ainda que a Reforma Universitária de 1968 tenha estabelecido o princípio norteador da associação entre o binômio pesquisa/ensino, os resultados, no decorrer do tempo, produziram "uma grande burocratização da pesquisa e uma enorme desvalorização da atividade docente" (CHAMLIAN, 1996, p. 3).

É nesta conjuntura de crise e desprestígio do "ethos acadêmico" que se precisa refletir sobre a questão central do tema - a formação do professor universitário - partindo das questões básicas que lhe são próprias:

- a viabilidade da associação entre o ensino e a pesquisa;

- o modelo pedagógico que sustenta esta formação docente;

- as reflexões e propostas apresentadas pelos especialistas no assunto.

No caso da formação do professor de História, não muito diferente da situação das demais áreas, percebe-se uma carência de discussões profícuas e sistemáticas sobre a sua particularidade.

Durante a realização deste trabalho, constatou-se uma escassez de textos - revistas e publicações universitárias - relativos ao ensino e a formação do docente em História. Esta lacuna é reveladora, pois aponta para a questão do papel da Universidade como formadora desse professor.

Uma pesquisa realizada por Claudia S. Ricci (1990, p. 142) revela esta situação. Segundo a autora, na Revista de História (1950-1977), com 120 números, somente 35 textos são dedicados ao ensino. $\mathrm{E}$, mesmo em suas seções intituladas "Questões Pedagógicas", o que aparece em geral são relatos de experiências.

Constatada a questão da ausência de uma investigação constante e consistente a respeito do assunto, é preciso, antes de tudo, para o desenvolvimento deste tema, discutir as especificidades e as características próprias do conhecimento histórico e de seu ensino. Conforme, Ciampi:

O permanente questionamento teórico-metodológico, existente na construção do conhecimento histórico, deve ser pensado também quando se indaga o que é ensinar história. As diferentes contribuições precisam ser discutidas e incorporadas para que possibilitem avançar também nas questões de sua transmissão. Isto porque as novas abordagens, ou novos objetos e os problemas da historiografia constituem o pano de fundo para 
a constituição dos procedimentos metodológicos de uma nova prática pedagógica. (1992, p. 265)

Feitas as ressalvas introdutórias, este artigo objetiva apresentar discussões e propostas levantadas, historicamente, sobre a questão da formação do professor de História do Ensino Superior, inseridas nos debates mais gerais sobre o assunto.

Para estes fins propõe-se uma periodização, em décadas, dos momentos significativos desse transcurso histórico.

\section{Dos ANOS 1930 AOS ANOS 1950}

A partir dos anos 1920, início do processo de modernização da sociedade brasileira, ocorreu um período fértil de manifestações de caráter social e cultural, no qual a Educação foi um tema recorrente. Surgiram propostas inovadoras para o sistema Educacional, pois este ocupou espaço significativo nos órgãos públicos. $\mathrm{O}$ Estado passou a definir o papel pedagógico das instituições de ensino no país, por meio da planificação da educação em âmbito nacional. Um suporte legislativo, como a Reforma de Francisco Campos, em 1931, respaldava tais necessidades, estabelecendo, entre outras medidas, a formação profissional dos já graduados em nível superior, prevendo a realização de cursos de especialização e aperfeiçoamento. Nesta época, para $o$ atendimento às necessidades do ensino e da pesquisa, certa preocupação com a formação do professor do ensino superior se manifestou com a criação das primeiras universidades brasileiras, entre elas a USP. Esses cursos foram oferecidos, dali para frente, de acordo com o entendimento particular de cada instituição sobre como deveriam ser e que objetivos alcançar, não contribuindo de maneira satisfatória e eficaz para a formação de pessoal qualificado (BERBEL, 1994).

Para atender a tais objetivos, além dos incentivos e das medidas locais e nacionais, optou-se pela importação dos conhecimentos externos necessários à formação dos primeiros catedráticos brasileiros.

Com esse intuito foram convidados docentes estrangeiros que participaram da então conhecida "Missão Francesa”. A “missão", no Brasil, auxiliou a estruturação da USP e da Faculdade de Filosofia, produzindo "um grande impacto pedagógico no meio relativamente acanhado para a época e contribuiu para a implantação efetiva da investigação e dos altos estudos em setores até então absolutamente desconhecidos em nossos meios" (HELÁDIO apud CHAMLAIN, 1996, p. 5). 
Relatos de professores das ciências humanas da USP, que viveram aquele período, confirmam que a "missão" introjetou pela primeira vez no ensino superior preocupações didáticas. Segundo França (DEPOIMENTOS, p. 152):

[...] os professores estrangeiros (em relação aos brasileiros) eram mais ligados aos alunos, [...] havia um bom relacionamento dos alunos com os mestres, [...] entre eles principalmente Braudel, [...] que constantemente indicava o que deveríamos fazer quando fôssemos professores, dando conselhos, transmitindo suas experiências no magistério. Suas aulas como as do professor Pierre Monbeig eram criativas, vibrantes.

Os depoimentos legitimam o comprometimento desses docentes quanto ao vínculo entre o ensino e a pesquisa. Petrone (DEPOIMENTOS, p. 143) ressaltava:

enquanto Braudel (História) interessava-se tanto pela docência como pela pesquisa, (França, Depoimentos, p. 152) [...] Pierre Monbeig (Geografia) que era excelente professor e excelente pesquisador [...] nunca dissociava uma coisa da outra, orientava o estudante de modo a fazer com que a pesquisa ingressasse na sala de aula, assim como a experiência ganha na sala de aula fosse aproveitada no trabalho de campo, sempre com estreita interação entre ensino e pesquisa.

Os ensinamentos e as práticas pedagógicas desses docentes contribuíram para a sensibilização dos futuros professores brasileiros quanto à preocupação com a pesquisa e o ensino. É revelador o depoimento do professor Florestan Fernandes (DEPOIMENTOS, p. 135), no tocante aos possíveis legados da "missão":

[...] no começo, por insegurança e falta de tempo negligenciava um tanto a preparação de aula, [...] explorando mal as potencialidades pedagógicas. Aos poucos, porém, a paixão pelas tarefas didáticas cresceu dentro de mim. Como o pesquisador, o professor precisa reduzir o conhecimento acumulado previamente ao que é essencial e, mais como pesquisador, deve defrontar-se com o dever de expor tal conhecimento de modo claro, conciso, elegante. Ao atingir esse patamar, o ensino perdeu, para mim, o caráter de um fardo e a relação com os alunos passou a ser altamente provocativa e estimulante para o meu progresso teórico e sociológico. 
Mesmo recebendo críticas de "recolonização intelectual" (Novaes, Depoimentos, p. 161), a "missão francesa" foi de suma importância acadêmica. Apesar de terem permanecido pouco tempo no curso e lhes tivesse sido vetada a cadeira de História do Brasil, "os franceses" foram responsáveis por importantes inovações para o campo histórico. Destaca-se a criação de uma associação de historiadores, distinta do Instituto de Geografia e História, que introduziu elementos de renovação dos estudos históricos do país, nos seus aspectos teórico-metodológico e historiográfico como também no ensino e na pesquisa. Isso porque, antes desses, a disciplina História do Brasil era ocupada por professores brasileiros, entre eles Taunay e depois Alfredo Ellis, historiadores com méritos, mas bastante tradicionais. À margem da renovação da historiografia mundial contemporânea, a cadeira de História do Brasil foi marcada pelo tradicionalismo até a entrada de Sérgio Buarque de Holanda. Quanto à importância dada, em especial, ao ensino de História, afirma Paulo Miceli:

Fernand Braudel, importa lembrar, sempre considerou o ensino uma das principais razões da produção do conhecimento histórico, abrindo-se aí valioso espaço para discussão de seu pensamento, principalmente num país como o Brasil onde a formação de professores tem sido posta em segundo plano nas universidades (grifo nosso), verificando-se uma espécie de abandono dos cursos de graduação e promovendo-se lastimável distanciamento do ensino básico, em benefício de uns poucos e presunçosos especialistas em quase nada, e para os quais - orientadores e orientandos- , quase sempre ensinar é atividade menor e de pouco prestígio (grifo nosso). (1998, p. 265)

Prossegue ainda Miceli (1998, p. 265), recorrendo à conferência pronunciada por Braudel em $1936^{1}$, que naquela época já enfatizava a indispensabilidade da pesquisa para a renovação do conhecimento:

[...] mas é no ensino que as coisas devem ser finalizadas, pensava Braudel, [...] sempre valorizando a "arte difícil de ensinar" História: a aula de História é uma viagem longa e difícil, para os aprendizes como para o guia, através do tempo e do espaço. Sejamos francos: viagem penosa, que há de exigir atenção, reflexão, esforço, compreensão e, direi ainda, viagem que é, e não poderia deixar de ser, tão somente instrutiva. Não é possível instruir-se [...] senão pelo constrangimento. Devemos repetir que 
a viagem histórica é um duro constrangimento, [...] devendo constituirse numa "penetração na vida passada em toda a sua ebulição". E já que $o$ adolescente que nos ouve tende a preferir o presente a esse passado de idéias abstratas, é preciso fazê-lo "viver na realidade da história, entre coisas concretas". E nossa missão, talvez, fazer com que entre largamente a vida no tumulto de idéias que provocam o espírito da infância e da juventude [...] "A vida das coisas, a vida dos seres".

Por isso Braudel insistiu sempre na importância da vida das coisas: "todo o acontecimento que tereis para contar tem um lugar no espaço e não se compreende fora de seu ambiente" (MICELI, 1998, p. 265-6).

\section{DoS ANOS 1950 AOS ANOS 1970}

Foi somente a partir dos anos 1950 que começaram a aparecer, além dos Programas de Mestrado e Doutorado, iniciativas de capacitação em nível de pós-graduação, obedecendo a padrões mais adequados e certamente com níveis de exigência superiores aos anteriores.

A política desenvolvimentista dos anos 1950 resultou num crescimento urbano industrial acelerado e conseqüentemente numa maior demanda quantitativa e qualificativa - por educação superior. A expansão das universidades e instituições de ensino superior isoladas, a criação do CNPQ e da CAPES estimularam diversos núcleos a se empenharem na formação de pessoal qualificado mediante cursos para graduados. Neste período, em razão da escassa oferta de cursos superiores, muitos profissionais ainda se especializavam no exterior, em programas de pós-graduação (BERBEL, 1994).

A Reforma Universitária, ao eliminar o regime de cátedras, instituiu a departamentalização em áreas de conhecimento, contribuindo, assim, para a fragmentação das áreas e dos conteúdos. Esse processo possibilitou novas propostas de ensino, impossíveis com a cátedra, e, entre outras mudanças, preparou o campo para a futura criação da disciplina de Metodologia do Ensino Superior (BERBEL, 1994).

O início dos anos 1960 foi marcado por uma grande preocupação do MEC quanto à expansão dos estudos pós-graduados no país, fosse para completar a formação do pesquisador, fosse para o treinamento dos especialistas altamente qualificados. Nesse período, delinearam-se as funções e os papéis dos cursos de pós-graduação: o Lato Sensu firmou-se no seu aspecto prático-utilitário e ao Stricto Sensu foi delegada a função de conferir grau de mestre e doutor. 
Além dessas conquistas, deve-se salientar o início da discussão a respeito da questão da complementaridade entre o ensino e a pesquisa e os papéis referentes a educadores e pesquisadores. Para tanto, pensou-se na criação da pós-graduação como possibilidade de conciliação entre essas duas formas de trabalho. Durante as décadas de 1960 e 1970 foram estabelecidos diversos dispositivos legais com o objetivo de aperfeiçoar a formação dos docentes do ensino superior. Contudo, mesmo depois de legalmente implantadas, parte dessas resoluções permaneceram com problemas relacionados à proposta inicial. Após o Golpe de 64, tais medidas foram acompanhadas por outras que repercutiram drasticamente no ensino e na formação docente dos professores das áreas das Ciências Humanas e Sociais, sobretudo no que se refere à implantação dos Estudos Sociais e suas diversas implicações.

Durante todos esses anos (1966-1980), pareceres, decisões, portarias e decretos foram elaborados para assegurar a viabilização dos Estudos Sociais. A implementação dos Estudos Sociais agravou consideravelmente a situação do ensino das humanidades, especialmente, no momento de se definir a formação do professor "qualificado" para ministrar tal disciplina. Este, segundo os critérios adotados, deveria ser "polivalente", preparado em curso universitário bastante amplo e generalizante e, portanto, com uma formação reduzida em suas pretensões e em seu conteúdo em relação à do pesquisador ou do bacharel (FENELON, 1986).

Enquanto no Brasil, entre as décadas de 1960/70 e início dos anos 1980, na área das Ciências Humanas, travava-se uma luta entre os profissionais para a extinção da disciplina Estudos Sociais, no exterior ampliava-se a discussão sobre a formação do professor do ensino superior. Segundo António Nóvoa (1992, p. 21), “a década de 70, é, também, um período fundador do debate actual sobre a formação de professores..., podendo mesmo argumentar que [...] a reflexão em torno da formação de professores cristalizou nesta altura [...]”.

Nesse período, a formação de professores do ensino superior de História recebeu contribuições, apresentadas no $3^{\circ}$ Caderno do Grupo de Investigação Didática, da Universidade de Quebec (Canadá) ${ }^{2}$.

Na sua definição sobre a formação dos professores de História, o Grupo de Investigação Didática sublinhava que:

o estudante-professor não será nem um psicopedagogo, nem um historiador, mas sim um professor de história. O grupo propunha, ainda, "abolir todas as distinções que existem entre os aspectos ditos metodológicos, profissionais, culturais e psicopedagógicos de um programa de formação de professores", e concluía: "se o professor de história no seu ato de 
ensino é um, é normal [...] que a preparação para este ato seja una. Nem psicopedagogo, nem historiador" (BERNARD, 1976, p. 194).

O "Grupo" advertia também sobre o corporativismo existente na formação exclusivamente profissional dos professores de História. Esse modelo resulta no "sacrifício" dedicado aos estudos pedagógicos o tempo que normalmente deveriam consagrar à aquisição de uma cultura geral e de uma sólida formação histórica. Assim, em seus ensaios, propõe que: "contra a fusão da preparação histórica e da preparação pedagógica, é preciso destacar, antes, a da sua coordenação [...] e a partir dela "chegar-se-ia à integração ou à fusão, em alguns cursos e em algumas experiências práticas de ensino [...]" (BERNARD, 1976, p. 196).

Os "historiadores canadenses", de um modo geral, levantaram também objeções quanto à tradição herdada do "curso magistral" vigente no ensino de História.

Criticado por professores que experimentavam outras fórmulas de ensino, o modelo tradicional, não de todo superado ${ }^{3}$, ganhava uma nova interpretação. Em razão das dificuldades de superação deste método de ensino, propunha-se que o "valor pedagógico de uma exposição magistral inteligentemente construída deve ser complementado por formas de ensino em que o estudante poderá, por seu turno, assumir a análise da realidade histórica, usando instrumentos metodologicamente adequados" (EID, 1976, p. 191).

\section{A DÉCADA DE 1980}

No Brasil, no decorrer da década de 1980, a formação de professores do ensino superior começava a ganhar certo espaço no meio acadêmico. Ressalta-se a realização, em 1985, do Seminário Itinerante - "Dependência Econômica e Cultural, Desenvolvimento Nacional e Formação de Professores". Neste encontro, intelectuais de várias áreas do conhecimento acadêmico discutiram temas relativos à educação brasileira, privilegiando a dimensão social e política e definindo marcos para a formação de professores.

Vale lembrar a recomendação da implantação da disciplina Metodologia do Ensino Superior, como disciplina pedagógica, na pós-graduação. Essa, na prática, tornou-se obrigatória somente em alguns cursos, como o de Medicina e de Odontologia, e para outros se configurou como disciplina optativa. Projetos inovadores de apoio pedagógico ao ensino superior, entre 
outros, foram realizados pelo Mackenzie e pela PUC-SP (durante a criação do Curso Básico).

Neste quadro de interesses gerais sobre a formação de professores, os profissionais de História, no Brasil, começam a discutir problemas específicos da formação de professores de sua área. Um artigo, histórico, abriu frente para futuras discussões e investigações sobre o assunto, até então escasso no meio universitário do curso de História. Trata-se da conferência da Dra. Déa Fenelon pronunciada no XI Simpósio Nacional da ANPUH, em João Pessoa, 1981, com o título "A Formação do Profissional de História e a Realidade do Ensino". $\mathrm{O}$ artigo - escrito nos tempos da ditadura militar e da luta contra os Estudos Sociais - teve o seu grande mérito em criticar, primeiramente, as concepções tradicionais de ciência, do saber, de produção do conhecimento e da posição dos historiadores como "fazedores de História". A autora polemizava os pressupostos teórico-metodológicos e historiográficos (abstratos e fragmentados), vigentes no ensino da História, dissociados que estavam de uma prática real. Tal concepção reflete na atomização das disciplinas dos Departamentos de História e na ausência de uma proposta didática consistente, relegando, assim, para um segundo plano a formação do professor de História (FENELON, 1983).

Com o fim da ditadura militar e o processo de redemocratização da sociedade brasileira, o ensino de História foi alvo de atenções dos profissionais envolvidos com sua qualidade. Novas experiências e alternativas isoladas propondo renovações no ensino da disciplina foram contempladas por inúmeros artigos ${ }^{4}$, produzidos, na sua maioria, por docentes da Universidade, voltados para a educação básica.

Nos anos 1980, iniciou-se a reformulação das Propostas Curriculares do Ensino de História da Rede Pública Estadual de São Paulo e de outros estados da união.

Este feito, que se desdobrou durante quase toda a década, teve o mérito de possibilitar a aproximação entre profissionais da educação básica e de inúmeras Universidades brasileiras, estabelecendo, assim, um diálogo promissor para o ensino de História e a formação do professor. Entre os resultados obtidos, deve-se mencionar o encontro nacional, em 1988, na USP, denominado "Perspectiva do Ensino de História”.

Os ANOS 1990

Foi a partir dos anos 1990 que a preocupação com a formação do professor de Ensino Superior ganhou corpo e consistência. Para António Nóvoa, 
[...] esta década [90] será marcada pelo signo da formação contínua de professores. Uma vez que os problemas estruturais da formação inicial e da profissionalização em serviço estão em vias de resolução, é normal que as atenções se virem para a formação contínua. Mas para concretizar tal projeção, o autor alerta que "é preciso fazer um esforço de troca e de partilha de experiências de formação, realizadas pelas escolas e pelas instituições de ensino superior, criando progressivamente uma nova cultura da formação de professores" (grifo nosso). (1992, p. 22)

Surge, também, nestes anos e no âmbito internacional, mais precisamente na França, especialistas investigando, com base em novos parâmetros, a questão da formação de professores, entre eles, Annie Bireaud. O tema, antes confinado a discussões particularizadas, começa a despertar atenção dos docentes das diversas áreas de ensino, conquistando espaços nas discussões acadêmicas.

No Brasil, destacam-se os trabalhos de Neusi Berbel - propondo uma discussão mais acurada e crítica a respeito da natureza e identidade da disciplina Metodologia do Ensino Superior e sua contribuição para a formação de professores universitários - e de Helena C. Chamlian - com sua pesquisa sobre a "Formação do Professor Universitário na USP".

No campo do ensino e da formação de docentes do ensino superior de História, a década de 1990 foi marcada pelas discussões entre historiadores sobre a problemática teórico-metodológica e historiográfica da disciplina. Há de se considerar, entre outros, o trabalho da professora Helenice Ciampi, de 1992, que, partindo de questões gerais sobre a formação de professores, particulariza a situação para a disciplina de História. Segundo a autora

o IV Encontro Nacional de Reformulação dos Cursos de Formação do Educador, 1989, preocupado em especial com a integração dos atuais cursos de bacharelado e licenciatura, a Comissão Nacional sugere uma base comum a todo país que expresse, para a formação do educador em qualquer área, um corpo de conhecimento básico, estruturado em três campos fundamentais: conhecimento específico, pedagógico e integrador. (1992, p. 263)

Com base nas colocações do dito documento, a autora menciona, entre outras indagações presentes naquele encontro, a relação entre ensino/ pesquisa. Para tanto, denuncia a distinção de universidades, uma vocacionada 
para a pesquisa (pós-graduação) e a desvalorização da graduação, a outra destinada "à formação de profissionais". Com isso, de acordo com Ciampi

consagrar-se-ia, desta forma, em definitivo, a separação entre ensino e pesquisa. Nada impede que se faça uma distinção entre universidade e instituição de ensino superior baseada na ausência ou não da pesquisa, porém, é preciso impedir que esta proposta leve ao descompromisso da Universidade para com o ensino na graduação. (1992, p. 264)

Nesse cenário, a autora enfatiza que

a questão da formação dos profissionais em educação é abordada, em diversas instâncias, tanto pelas várias áreas que pensam a educação, quanto pelas demais áreas específicas do conhecimento. A diversidade de pressupostos e perspectivas nos permite confrontar diferentes posições na sua organização teórica e propostas operativas. A competência e as contribuições das áreas específicas do conhecimento, entre elas a da História, são fundamentais para a formação profissional. (1992, p. 265)

Esta formação profissional remete inicialmente à discussão da especificidade do conhecimento histórico. Como o processo histórico está sempre agregando novos acontecimentos, que passam por constantes releituras, tratase de um conhecimento também em constante movimento. Nesse sentido, o historiador é, igualmente, sujeito do conhecimento e da História, ficando submetido às determinações e aos limites do seu tempo e aos conhecimentos sociais que lhes são colocados.

Há, portanto, diferentes maneiras de apreender o histórico e, dessa forma, a história é reescrita segundo preocupações e diferentes pontos de vista, que são, também, historicamente condicionados. A História é o produto de uma situação, de uma história, isso obriga os historiadores, já conscientes dessa relação, a se interrogarem novamente sobre os fundamentos epistemológicos de sua disciplina. Deve-se questionar não só o ensino de história, mas a própria história e os seus pressupostos teórico-metodológicos como objeto de conhecimento. É valendo-se destas considerações a respeito da natureza do conhecimento histórico que se insere a constituição dos procedimentos metodológicos de uma nova prática pedagógica. Por isso, conforme a autora, "o conhecimento histórico deveria ser encarado em qualquer organização curricular em sua tríplice dimensão: produzir, criticar e transmitir” (CIAMPI, 1992, p. 266). 
Esta compreensão baseia-se na necessidade de superar a dicotomia ensino-pesquisa, pois em História o que existe é a produção do conhecimento, que se processa de forma diferenciada nos diferentes níveis. O professor de História deve não apenas dominar o conteúdo, mas também saber como ele é produzido e ter uma visão crítica do trabalho histórico existente. Para que isso seja possível, torna-se necessário, nos centros de formação de professores e nas universidades, associar, integrar definitivamente o ensino à pesquisa; fornecer o conteúdo, o conhecimento já organizado de forma sistemática e possibilitar a elaboração de um novo conhecimento e/ou o desenvolvimento do que já existe (Silva Fernandes, 1996).

Nesse sentido, ensinar história é, em todos os níveis, instigar a possibilidade da construção do objeto de conhecimento histórico, situar-se na historiografia, entre outros. Como a produção do conhecimento histórico é complexa, essa nos diferentes níveis de ensino precisa ser pensada quanto a sua transposição didática.

Em relação à Universidade, esta acaba produzindo, num nível mais "aprofundado", os mesmos temas e periodizações que tanto denunciam no ensino fundamental e médio, não conseguindo, portanto, romper as práticas que discursivamente critica (Ciampi, 1992).

Assim, no ensino superior de História, tanto as disciplinas ditas de "conteúdo" como as "teóricas" deveriam ser unificadas, ou seja, não abordadas de forma "abstrata" e dicotomizadas em relação ao conteúdo, mas sim trabalhadas de forma articulada e com conteúdos temáticos específicos.

Esta visão compartimentada da formação profissional de história decorre não apenas da separação entre bacharelado e licenciatura, mas também entre ensino e pesquisa, entre teoria e conteúdo, que se não são vistos como opostos, pelo menos com níveis de exigência diferenciados (Ciampi, 1992).

Na realidade, na maioria dos Cursos de Graduação em História, as discussões teóricas, metodológicas e historiográficas restringem-se ao âmbito das disciplinas denominadas "Introdução aos Estudos Históricos", "Metodologia da História" e "Teoria da História" (Fenelon, 1985). As demais disciplinas passam ao largo dessas discussões, como se seu papel fosse, exclusivamente, transmitir "o conhecimento" produzido sobre determinados temas, não refletindo sobre a diversidade existente no interior desse conhecimento, seus fundamentos teóricos e metodológicos.

Essa pobreza teórica poderia ser "compensada" por uma "vivência prática" satisfatória. No entanto, não o é, nem poderia ser diferente: "nossos alunos não realizam investigações de natureza histórica, não vivenciam situ- 
ações de pesquisa na Universidade, não produzem conhecimento histórico, enfim, não fazem história" (Villalta, 1992-1993).

No interior dos próprios Departamentos de História, inexiste articulação: prolifera a atomização e leva-se ao extremo a máxima "cada professor, sua sentença". "À simples proposta de discutir objetivos, sentido do que se quer propor, estratégias etc., surge imediatamente a terrível palavra: $\underline{\text { isto }}$ é coisa de pedagogos! O sentido pejorativo da colocação é evidente no discurso dos profissionais de conteúdo" (Fenelon, 1983). E, assim, ganha espaço e atomização a pobreza teórica didática dos professores do ensino superior.

Em suma, os Cursos de Graduação em História, ainda hoje, além de não formarem pesquisadores, fracassam igualmente na formação de professores. Os alunos saem com formação precária do ponto de vista teórico e, mais do que isso, quase sem vivenciarem a Prática de ensinar História. Tangencia-se a teoria e negligencia-se a prática nos Cursos de Graduação em História: eis a nossa participação na formação do "professor real" (Villalta, 1992-1993).

Em 1996, foi realizado o II Encontro - Perspectivas do Ensino de História - Faculdade de Educação - Universidade de São Paulo. O tema central desse evento foi sobre as reformulações curriculares da área de História, considerando-se a série de mudanças que estavam ocorrendo nesse campo naquela época.

Perspectivas para o InÍCIO dA déCAda 2000

No ano 2000, o MEC emitiu um documento - "Proposta de diretrizes para a formação inicial de professores da educação básica, em cursos de Nível Superior"- que propunha, como pressuposto básico, a necessidade de estabelecer, em novos parâmetros, uma política nacional de formação de professores. As orientações contidas no documento apresentam referências para que as instituições formadoras possam, no exercício de sua autonomia, formular e organizar seus próprios projetos pedagógicos e ao mesmo tempo sugere, entre outros:

- definição de todas as licenciaturas como plenas;

- reafirmação do ensino Superior como nível desejado para a formação de professores;

- busca de proficiência na formação superior de professores;

- integração entre a formação de professores que atuam nas diferentes etapas de escolarização. 
Além dessas sugestões gerais, a "Proposta" aponta para a importância de que as instituições formadoras, no momento de definir os seus conteúdos curriculares, incluam um conjunto de competências referidas a serem complementadas pelas competências específicas da área de conhecimento para a estruturação de seus projetos de formação de professores.

Neste contexto, chama atenção para a questão da "formação dos formadores" no âmbito da academia, tanto para os cursos de graduação como também para os cursos de pós-graduação, pois esses precisam ter presentes estas exigências, de modo a não desconsiderarem os elementos pedagógicos que devem ser incluídos na formação dos docentes para o ensino superior, uma vez que serão eles os preparadores dos futuros professores, nas diversas modalidades de cursos formadores de docentes para os vários níveis de ensino.

Mais recentemente, a problemática da formação do professor ganhou espaço na mídia conforme avaliação atualizada por Guiomar de Mello (2009, p. 89), que apresenta um cenário desolador em relação à atuação profissional dos professores da educação básica e sua formação acadêmica: "grande parte dos docentes no Brasil se forma sem saber o que nem como ensinar. As faculdades se perdem em teorias dissociadas da prática em sala de aula e não cumprem sua função básica: formar um profissional realmente capaz de exercer seu ofício".

\section{THE UPBRINGING FROM THE UNIVERSITY PROFESSOR OF HISTORY}

АвsтRACт: The present article intends to reflect, historically, the problematic of the upbringing from the university professor of History in Brazil, centered in the bipolarity education/research as "academic ethos" which supports the idea of University.

KeY WoRDs: history, education, professor upbringing

\section{NOTAS}

1 Cf. Conferência pronunciada em setembro de 1936 no Instituto de Educação da Universidade de São Paulo, publicada pela primeira vez nos Archivos do Instituto de Educação, ano II, n. 2 e reeditada pela Revista de História, v. 11, n. 23, jul./ set. 1955, p.3-21 (Miceli, 1998, p. 461).

2 Trata-se de La formation de l'enseignant d'histoire. Rechereche d'une pédagogie, Trois-Rivières, Editions du Boréal Express, 1968, e de L'enseignement de l'histoire au niveau universitaire, de Michel Allard, publicado no mesmo editor em 1970. 
3 "Segundo BIREAUD, o modelo pedagógico tradicional da universidade, traduzido pela "aula magistral", ainda não teve sua lógica rompida, a despeito da incorporação de inovações de natureza tecnológica, representadas pela utilização dos meios e recursos audiovisuais e da informática" (Chamlian, 1996, p. 5).

4 História em Quadro Negro. Revista Brasileira de História, São Paulo, ANPUH/ Marco Zero, v.9, n. 19, set.1989 - fev.1990. Repensando a História. Marcos A. Da Silva (Org.). São Paulo: ANPUH/Marco zero, s/d. O Ensino de História: revisão urgente. Cabrini, Conceição et al. São Paulo: Brasiliense, 1986.

\section{REFERÊNCIAS}

BERBEL, Neusi. Metodologia do ensino superior: realidade e significado. Campinas: Papirus, 1994.

BERNARD, Jean-Paul. Algumas interrogações sobre a formação dos professores de História. In: ALLARD, Michel et al. A história e seu ensino. Coimbra: Almedina, 1976, p.193-200.

BIREAUD, Annie. Os métodos pedagógicos no ensino superior. Porto: Porto Ed., 1995. CHAMLIAN, H. C. A formação do professor na USP. Relatório de Pesquisa (CNPQ). São Paulo, 1996.

CIAMPI, Helenice. Poder, Cidadania e Formação profissional de História. Jogos da Política - Imagens, Representações e Prática. São Paulo: ANPH/Marco Zero, s/d, p. 259-269.

EID, Nadia F. Para uma metodologia mais exigente da aprendizagem. História. In: ALLARD, Michel et al.A História e o seu Ensino. Coimbra: Almedina, 1976, p. 187-192.

FAZENDA, Ivani C. A. A busca de identidade numa prática de ensino. Encontros e Desencontros da Didática e da Prática de Ensino. Cadernos Cedes 21. São Paulo: Cortez, 1988, p. 13-17.

FENELON, Déa Ribeiro. A formação do profissional de História e a realidade do ensino. Caderno Cedes 08. São Paulo: Cortez, 1985, p. 25-31.

FENELON, Déa Ribeiro. A Questão de Estudos Sociais. Caderno Cedes 10. A prática do ensino de história. São Paulo: Cortez, 1986, p.11-22.

MASETTO, Marcos Tarcisio. Pós-graduação: rastreando o caminho percorrido. In: SERBINO, Raquel Volpato. et al. (Orgs.) Formação de Professores. São Paulo: Editora da UNESP, 1998.

MEC. Proposta de diretrizes para a formação inicial de professores da educação básica, em cursos de Nível Superior. Brasília, mai. 2000 (Mimeo). 
MELLO, Guiomar Namo de. Escola para Professores. VEJA, São Paulo, n. 2.112, p. 89, 13 maio 2009.

MENEZES, Luiz Carlos. Formar professores: tarefa da Universidade. In: Anais do Seminário Itinerante: Dependência Econômica e Cultural, Desenvolvimento Nacional e Formação de Professores. São Paulo, Edusp, 1985.

MICELI, Paulo. Sobre História, Braudel e os Vaga-Lumes. A Escola dos Annales e o Brasil (ou vice-versa). In: FREITAS, Marcos Cezar de (Org.). Historiografia Brasileira em Perspectiva. São Paulo: Contexto, 1998.

NÓVOA, António. Formação de professores e profissão docente. In: NÓVOA, António Nóvoa (Coord.). Os Professores e a sua Formação. Lisboa: Publicações Dom Quixote, 1992.

OLIVEIRA VALADARES, Ione Maria de; SILVA PRADO, Luiz Fernando. Proposta de formação inicial de professores. Secretaria de Estado da Educação de Goiás, Goiânia, ago. 2000. (mimeo).

RICCI, Claudia Sapag. A academia vai ao ensino de $1^{\text {o. }}$ e $2^{\text {o. }}$ graus. História em Quadro-negro - Escola, ensino e aprendizagem. Revista Brasileira de História, São Paulo, ANPUH/Marco Zero, v. 9, n. 19, set. 1989; fev. 1990, p. 135-142.

RUIZ SILVEIRA, Nádia Dumara. Abrindo parênteses: os fundamentos da educação e a docência no ensino superior. Encontros e Desencontros da Didática e da Prática de Ensino. Cadernos Cedes 21. São Paulo: Cortez,1988, p. 25-46.

SILVA FERNANDES, Irene Rodrigues. História da América no $3^{\circ}$ Grau: reavaliação e propostas para o estudo universitário. In: Bittencourt, Circe Maria F.; IOKOI, Zilda Márcia Gricoli (Coord.). Educação na América Latina. Rio de Janeiro: Expressão e Cultura; São Paulo: EDUSP, 1996.

USP, ESTUdOS AVANÇAdOS 22. Depoimentos Perfis de Mestres. São Paulo, s/d.

VILLALTA, Luiz Carlos. Dilemas da relação teoria e prática na formação do professor de História: alternativas em perspectivas. Memória, História, Historiografia - Dossiê ensino de História. Revista Brasileira de História, São Paulo, Anpuh/Marco Zero, vol. 13, n. 25/26, set. 1992, ago. 1993. p. 223 -232. 